\title{
Private and Public Resources Impacts on the Development of Global Perspective in China
}

\author{
Yuen-Hang Ng1, Raymond K. H. Chan' ${ }^{2}$, Min Hu${ }^{1}$ \\ ${ }^{1}$ Department of Social Work, Chinese University of Hong Kong, Hong Kong, China \\ ${ }^{2}$ Department of Social and Behavioural Sciences, City University of Hong Kong, Hong Kong, China \\ Email: yhng@swk.cuhk.edu.hk
}

How to cite this paper: Ng, Y.-H., Chan, R.K.H. and Hu, M. (2018) Private and Public Resources Impacts on the Development of Global Perspective in China. Open Journal of Social Sciences, 6, 48-62. https://doi.org/10.4236/jss.2018.69004

Received: August 9, 2018

Accepted: August 31, 2018

Published: September 3, 2018

Copyright ( 92018 by authors and Scientific Research Publishing Inc. This work is licensed under the Creative Commons Attribution International License (CC BY 4.0).

http://creativecommons.org/licenses/by/4.0/

\begin{abstract}
Achieving a global perspective has become essential under globalization, and thereby both China government and the parents have increased spending on global perspective education. Resource theory posits private and public resources can have positive social impacts. Nevertheless, the independent and interactive impact of private and public resources on global perspective remains underexplored. Through a survey applied on 645 high school students in Shenzhen, China, the results show that only household income has an independent positive effect on global perspective. Notably, there is a positive effect on global perspective from the interaction of household income and district GDP. This possibly suggests the limitations in the manner of public resources distribution. To rectify it, public resources should be more targeting to students in needs to minimize social inequality.
\end{abstract}

\section{Keywords}

Private Resources, Public Resources, Global Perspective, China, Shenzhen

\section{Introduction}

Globalization is a multi-faceted and complex phenomenon due to its heterogeneous pace of development across countries and its attendant ethical considerations [1]. One of the facets of globalization is the development of the global citizen [2]. In order to become a global citizen, it is necessary to acquire a global perspective as a youth. Through global perspective education, young people become aware of current issues throughout the world and develop the critical thinking, empathy and wide-ranging perspective that characterize the global citizen. The differences between those who acquire such skills and those who do not are likely to deepen the social divisions and marginalization that are already 
prevalent in the nation as well as in the world.

Education aimed at providing a global perspective is gaining increased attention due to the growth in international relations culturally, commercially and ideologically [3]. To respond to this challenge, the Chinese government announced the Outline of the National Plan for Medium and Long-Term Education Reform and Development (2010-2020) in 2010, which stresses the importance of developing global perspective (officially referred as "international understanding" in China). Cities across China have introduced various policies to foster global perspective education. This is especially the case in Shenzhen, a city in Southern China that joined the free market in 1980, which has pioneered and piloted curricula and teaching materials. The Shenzhen government also launched the Plan of promoting global perspective in Shenzhen (2013-2020), which aims to introduce global perspective education at $95 \%$ of primary and secondary schools by 2020. In keeping with the 13th Five-Year Plan, the city and district governments have drafted specific plans related to educational development, which include the promotion of global perspective and internationalization of education.

Studies have shown how various types of resources contribute to the creation of global citizens. Monetary, educational and physical resources all have a part to play in developing a global perspective [1] [4]. The effects of certain attributes can be explained by resource theory. However, the effects of private and public resources, and the relevance of resource theory on the development of global perspective remain uncharted, owing to a lack of relevant empirical research. In Shenzhen, households have high incomes and its per capita GDP ranked the third in 2017, following Beijing and Shanghai, as according to the Shenzhen Statistics Bureau. It provides an interesting case to determine the effect of relatively abundant resources on students' global perspective. This study aims to illustrate how resources from the two major sources-the household (individual) and the district (communal) -influence global perspective and, especially, how they interact to foster the development of a global perspective, based on an empirical study of the city of Shenzhen.

\section{Global Perspective and Its Dimensions}

Global perspective, which generally refers to the development of the knowledge, skills and attitudes required to survive in a world with limited natural resources, is characterized by ethnic diversity, cultural pluralism and increasing interdependence [5]. Initially, it grew to prominence in Western countries, but it has gradually attracted wider attention, including that of China [6]. Global perspective can be characterized by various dimensions. The United Nations Educational, Scientific and Cultural Organization (UNESCO) [7] identifies cognitive, socio-emotional and behavioral dimensions of global perspective. The cognitive dimension includes one's understanding, knowledge attainment and critical thinking; the socio-emotional dimension involves sharing values, respect for 
diversity and sense of belonging to a common humanity; and the behavioral dimension is based on the expectation that people will act responsibly in local, national and global communities. The Organisation for Economic Co-operation and Development (OECD) [8] identifies the elements of global perspective as knowledge and understanding, attitudes, values and skills. The attitudes of both international organizations are very similar: Global perspective includes knowledge, attitudes and values, and the capacity to interact respectfully, appropriately and effectively.

Scholars have also identified certain dimensions of global perspective. Hanvey [9], who coined the term "global perspective," held that it had five dimensions: perspective consciousness, state-of the planet awareness, cross-cultural awareness, knowledge of global dynamics, and awareness of human choice. Case [10] elaborated on Hanvey's global perspective by differentiating between substantive and perceptual dimensions: the substantive dimension is knowledge of world culture and international issues; whereas the perceptual dimension is a perspective on knowledge that is open-minded, nuanced, empathetic and unbiased. Even though scholarly definitions of global perspective vary, they all share the four dimensions of knowledge, attitude, skills and behaviors. Following these dimensions, we develop a Global Perspective Scale to test the respondents' global perspective, as well as testing the effects of public and private resources.

\section{Resource Theory}

Resource theory is based on the premise that individuals use resources, which are transformed into the power to fulfill their needs [11]. With resources, individuals are capable of surviving and making adjustments in an ever-changing environment [12]. Under globalization, people face various uncertainties, including increasing competitiveness among countries and labor markets, and changing societal structures [13] [14]. The cultivation of global citizens is essential to survival, and will also contribute to a more cohesive and harmonious world [15]. In order to achieve a global perspective, an individual requires resources. A resource is an objective entity, existing in a material, physical or economic form, which can be obtained through production, borrowing, and social rights [16].

Of all the kinds of resources, financial resources, measured by household income and district GDP, play the key role in supporting children's education [17]. Household income is more readily available and accessible, and is therefore the more likely to foster a child's educational attainment of a global perspective [18]. For instance, a child's global perspective is enhanced by proficiency in other languages and by study abroad programs [19]. Through such experiences, youths accept cultural diversity and build intercultural communication. Household income, then, can have a direct effect on children's exposure to global perspective [20]. Youths with higher household income can take more opportunities to satisfy educational goals, including global perspective. 
Chinese families focus on their responsibilities towards family members, and children's success is a matter of family pride. The success of parents is evident in their children's achievements. Of the various paths to the achievement, education is one of the most promising. A student's ability in all subjects, including acquisition of global perspective, is highly valued and prioritized. The number of Chinese students studying internationally has been increasing; they account for a large portion of all students studying internationally. According to the statistics compiled by Ministry of Education, in 2014, 459,800 students studied internationally, and the number rose to 608,400 in 2017. Among those who travelled overseas for study, $88.97 \%$ funded their own travels. This trend suggests that Chinese parents who can afford to do so will support their children's acquisition of international experience.

Parents, who in all countries act as resource providers, play a particularly crucial role in China. According to Confucian teaching, the main responsibility of parents is to lead their children on the path to success and encourage them to become pillars of society. Youths, in turn, are expected to make use these resources to achieve academic excellence, which is a means of expressing filial piety and honoring their parents, the community and even their country.

District GDP is a monetary measure of the financial resources of a particular locality. Affluent local governments have the greater potential and flexibility to meet strategic goals, including investment in the promotion of global perspective. District GDP has been shown to have a positive correlation with overall and education expenditures. Total local government education expenditure in Shenzhen increased from RMB 15.2 billion in 2012 to RMB 41.5 billion in 2016, an almost threefold increase in five years, while city GDPs grew by $50 \%$ [21]. In more developed districts, with higher GDPs and government expenditure, such as the Futian and Baoan districts of Shenzhen, global perspective education has become a strategic priority [22] [23].

Global perspective education requires more public financial spending than other subjects [24]. Unlike the conventional curriculum, global perspective courses emphasize intercultural experiences and foreign language skills, which are vital to participation in a global context. To encourage students to acquire such competencies, schools must provide an array of activities in addition to the regular curriculum. Such activities can include cultural festivals, student and staff exchanges, foreign teachers and international partnerships. All these initiatives require extra resources [25] [26]. Furthermore, this type of education must be of a high quality, which can be a challenge for school administrators and teachers who have not acquired global competencies themselves [27]. In such cases, monetary resources must also be provided to train instructors to teach global perspective.

In summary, district GDP, as an indicator of district affluence, is a resource that contributes to global perspective initiatives. A higher district GDP gives local governments more monetary resources to achieve their strategic goals [17]. 
In Guiding Opinion on the Comprehensive Deepening of Secondary and Primary Education Curriculum Reform, the Shenzhen City Education Bureau [28] made it clear that "promoting international understanding education and promot[ing] internationalization of education" are key policy objectives. Various district governments have pledged funding for new curriculum designs, language education, cultural exposure programs, staff training and exchanges, student exchanges and overseas exposure programs, school partnerships, hiring of foreign teachers, and other means of encouraging global perspective.

Resource theory deals with individual and public resources. Income and district GDP, representing individual and public monetary resources, respectively, are of paramount importance in global perspective education [18] [29]. Theoretically, the effects of household income and district GDP could be combined to further contribute to global perspective education. Increasing public expenditure might offer a possibility to mitigate the problem causing by wealth gap. Public resources can work to level the playing field, minimizing the negative impacts of a lack of private resources [30]. Hence, particular attention should be paid to the ways in which they interact with each other to produce positive effects, such as minimizing inequalities and providing opportunities [31].

However, there is also the view that public resources might not be able to deliver the objective. A positive interaction of public and private resources depends on the nature of the expenditure and the individual agents' management of the resources [32] [33]. Depending on the structure of provisions, the middle class could benefit more than the working class from the extension of social services and the reduction of the tax burden. Moreover, the middle class, who possess relatively more resources, measured in knowledge and financial terms, than that of working class, could utilize the information of service sponsored by public resources to foster global perspective [34].

The available literature examines the resources that have an effect on global perspective, but there is little empirically based analysis, especially in the context of China [6]. The literature also does not examine the interaction between types of resources, in particular that of household income and district GDP. This study aims to determine which resources aid in the development of global perspective and especially the effect of the interaction of these resources.

\section{Hypotheses}

The ideas outlined in the discussion above led to the formulation of the following hypotheses:

H1: Household income correlates positively with the development of global perspective.

H2: District GDP correlates positively with the development of global perspective.

H3: The interaction between household income and district GDP has a positive effect on global perspective education. 
When testing hypotheses, it is necessary to control for demographic characteristics because they could confound the hypothesized effects. Controlling for such characteristics could uphold the significance of hypothesized effects on global perspective. In this case, such characteristics include age, gender, youth's educational attainment and parents' educational attainment. For instance, research has shown that age can have equivocal effects on global perspective. Sometimes its impact is positive: age can be a time of wisdom and of adaptation to ever-changing conditions, including globalization [35]. Its impact may also be negative, as the elderly tend to become less conscious of world events. Studies have also shown that women are more motivated than men to embrace a global perspective owing to the increased employment opportunities under globalization [1]. Educational attainment has also been shown to be beneficial to global perspective because it enhances people's knowledge of the world and enables them to deal with uncertainties and be flexible enough to make the adjustments required by globalization [36]. Finally, parents with a high level of education are likely to foster their children's aspiration to obtain a higher education, and thus the development of global perspective [37].

\section{Hypotheses}

\subsection{Procedure and Participants}

The sample for this study included 645 high-school students who, in January and February of 2018, were recruited from high schools in every administrative district of Shenzhen city, except one district that did not provide senior secondary education. Most of these students were interviewed in person, but an online survey was also conducted through a dedicated internet platform to solicit more respondents. The sample comprised 599 interviewed respondents and 46 surveyed respondents. Of these, $42.2 \%$ were male and $57.8 \%$ were female, and the average age was 17.0 years $(\mathrm{SD}=0.33$, see Table 2 ). The majority of the participants (93.6\%) were in their second year of senior secondary education (Table 1).

\subsection{Measurement}

This study used a custom-designed Global Perspective Scale (Table 2). The design of questionnaire involved three steps. First, a draft was prepared, based on the key dimensions identified in global perspective instruments such as the PISA Global Competency Framework [8], the Global Understanding Survey [38], and the Global Perspective Inventory [39]. Second, several scholars in the fields of education, sociology and social research, as well as secondary school teachers, were invited to comment on the first draft of the questionnaire and to verify its suitability and validity. As a result of their input, a trial version of the questionnaire was created with 60 questions. Finally, we invited some high-school students in Shenzhen to complete the trial version and provided further suggestions on the questionnaire design. Based on their suggestions, wordings were modified and the questions were reduced to 49 . 
Table 1. Profile of respondents.

\begin{tabular}{|c|c|c|c|}
\hline Demographic factors & Items & Number & $\%$ \\
\hline \multirow{3}{*}{ Gender } & Male & 272 & 42.2 \\
\hline & Female & 373 & 57.8 \\
\hline & Total & 645 & 100 \\
\hline \multirow{4}{*}{ Age } & $15-16$ & 17 & 2.7 \\
\hline & 17 & 607 & 94.1 \\
\hline & $18-20$ & 21 & 3.3 \\
\hline & Total & 645 & 100 \\
\hline \multirow{4}{*}{ Educational level } & $1^{\text {st }}$ year of senior secondary education & 19 & 2.9 \\
\hline & $2^{\text {nd }}$ year of senior secondary education & 604 & 93.6 \\
\hline & $3^{\text {rd }}$ year of senior secondary education & 22 & 3.4 \\
\hline & Total & 645 & 100 \\
\hline \multirow{6}{*}{ Father educational level } & Primary education or less & 21 & 3.3 \\
\hline & Junior secondary education & 42 & 6.5 \\
\hline & Senior secondary education & 57 & 8.8 \\
\hline & Undergraduate education & 326 & 50.5 \\
\hline & Postgraduate education & 199 & 30.9 \\
\hline & Total & 645 & 100 \\
\hline \multirow{6}{*}{ Mother educational level } & Primary education or less & 20 & 3.1 \\
\hline & Junior secondary education & 74 & 11.5 \\
\hline & Senior secondary education & 99 & 15.3 \\
\hline & Undergraduate education & 283 & 43.9 \\
\hline & Postgraduate education & 169 & 26.2 \\
\hline & Total & 645 & 100 \\
\hline \multirow{6}{*}{ Monthly income } & RMB 5,000 or less & 21 & 3.3 \\
\hline & RMB 5,001 - 10,000 & 93 & 14.4 \\
\hline & RMB $10,001-15,000$ & 114 & 17.7 \\
\hline & RMB $15,001-20,000$ & 164 & 25.4 \\
\hline & RMB 20,001 or above & 253 & 39.2 \\
\hline & Total & 645 & 100 \\
\hline
\end{tabular}

Table 2. The reliability of Global Perspective Scale.

\begin{tabular}{|c|c|c|c|c|}
\hline Dimension & Sub-dimension & $\begin{array}{l}\text { Number } \\
\text { of items }\end{array}$ & $\begin{array}{l}\text { Reliability of the } \\
\text { sub-dimension }\end{array}$ & $\begin{array}{l}\text { Reliability of Reliability of } \\
\text { sub-scale the scale }\end{array}$ \\
\hline \multirow{3}{*}{ Knowledge } & Language proficiency & 1 & - & \multirow{3}{*}{0.94} \\
\hline & Global knowledge & 5 & 0.90 & \\
\hline & National knowledge & 5 & 0.91 & \\
\hline \multirow[t]{3}{*}{ Attitude } & Concern about global issues & 9 & 0.91 & \multirow{3}{*}{0.94} \\
\hline & Openness & 5 & 0.82 & \\
\hline & $\begin{array}{l}\text { Respect for the diversity of } \\
\text { global issues }\end{array}$ & 6 & 0.85 & \\
\hline
\end{tabular}




\begin{tabular}{|c|c|c|c|c|c|}
\hline \multicolumn{6}{|l|}{ Continued } \\
\hline & $\begin{array}{c}\text { Attitude towards global } \\
\text { identity }\end{array}$ & 5 & 0.81 & & \\
\hline & $\begin{array}{c}\text { Attitude towards national } \\
\text { identity }\end{array}$ & 4 & 0.84 & & \\
\hline Skills & $\begin{array}{l}\text { Skills in global } \\
\text { communication }\end{array}$ & 5 & & 0.80 & \\
\hline Behaviors & $\begin{array}{c}\text { Behaviors facilitating global } \\
\text { perspective }\end{array}$ & 4 & & 0.60 & .93 \\
\hline
\end{tabular}

The questionnaire included two types of resources: household income and district GDP), and demographic variables such as age, gender, educational attainment, and paternal and maternal educational attainment, in order to identify the contribution of each resource to global perspective. This questionnaire was self-administrated. For the sake of interpretation and comparison, the answers generated scores ranging from 0 to 100 [40].

The Global Perspective Scale includes four dimensions-knowledge, attitude, skills and behaviors-measured on a scale from 1 to 5 . The rating of the answers were converted to a score of $0,25,50,75$ or 100 for the five levels, representing a 0 to 100 scale, with the exception of the answers for behaviors, which had only two levels and were converted to a score of 0 or 100. The reliability of Global Perspective Scale was 0.93 .

The measures for knowledge included language proficiency, global knowledge and national knowledge. The language proficiency measure referred to proficiency in a foreign language and ranged from 1 for a complete lack of proficiency to 5 for fluency. The global knowledge measure was based on five questions rating knowledge of global culture, history, geography, politics and economy (e.g., How much do you know about the culture of foreign countries?), with scores ranging from 1 for very little knowledge to 5 for extensive knowledge. Similarly, the measure for national knowledge was based on five questions rating knowledge of local cultural, history, geography, politics and economy (e.g., How much do you know about your local culture?), with scores ranging from 1 for very little knowledge to 5 for extensive knowledge. The reliability was 0.94 .

With respect to attitude, nine questions were used to determine the participants' level of concern about global issues (e.g., How concerned are you about global conflicts?), with scores ranging from 1 for not concerned to 5 for very concerned. A further twenty questions were asked to determine the participant's openness to global issues, respect for diversity, and attitudes towards global and national identity. The scores ranged from 1 (total disagreement) to 5 (total agreement). A typical question was, "To what degree do you agree with the statement that you are willing to understand the culture of people in foreign countries?" The reliability of this measure was 0.94 .

Five questions were used as measures of skills in global communication, with scores ranging from 1 (total disagreement) to 5 (total agreement). A typical 
question was, "To what degree do you agree with the statement that you are capable of understanding a foreigner who has a different perspective?" The reliability was 0.80 .

There were four questions to determine behaviors, with a score of 0 for the answer "no" and 1 for the answer "yes." A typical question was, "Did you go on a foreign study tour in the past year?" The reliability was 0.60 .

Household income was rated on a scale from 1 to 5, with 1 representing RMB 5,000 or less per month and 5 representing RMB 20,001 or more per month. Later the scores were converted to the 0 to 100 scale. District GDP referred to the gross domestic product of the Shenzhen districts where our survey was conducted, including Futian, Luohu, Yantian, Nanshan, Baoan, Longgang, Longhua, Pingshan and Guangming. The 2016 GDPs of such districts were scored according to three points on a 0 to 100 scale, with 0 for a district GDP less than RMB 100 billion, 50 for a district GDP from RMB 100 billion to 200 billion, and 100 for a district GDP of more than RMB 200 billion.

Age was represented by the number corresponding to the participant's age. Gender was a dummy variable with 0 signifying female and 1 signifying male. The scoring procedure converted these to a 0 to 100 scale where $0=$ female and $100=$ male. Educational attainment was based on a youth's educational level and rated on a three-point scale. Later, the scoring procedure was converted to a 0 100 scale, with 0 representing placement in the first senior year, 50 in the second senior year and 100 in the third senior year.

Paternal and maternal educational attainments referred to the highest educational level the participants' parents attained on a 1 to 5 scale, with 1 referring to primary education or less and 5 referring to postgraduate education. Later, the scale was converted to from 0 to 100 , with 0 for primary education or less and 100 for postgraduate education or more.

\section{Results}

Global perspective was moderately high ( $M=64.5$, see Table 3$)$. Generally, the participants' educational attainment was at a modest level $(M=50.2)$, whereas their fathers and mothers had high educational attainments $(M=74.8$ and 69.7). The average household income and district GDP were relatively high $(M=70.7$ and 67.2, respectively). Generally, these descriptive findings demonstrate that Shenzhen is a city with a high economic development.

According to the bivariate analyses, paternal educational attainment, maternal educational attainment and household income showed significant positive correlations with global perspective, and being male showed significant negative correlations with global perspective ( $r=-0.09$ to 0.29 , see Table 4 ). Household income showed the strongest correlations with global perspective. Generally, such findings lent preliminary support to the hypotheses, in particular to the contribution of household income to global perspective.

Linear regression analysis indicated that household income showed a significant positive impact on global perspective ( $\beta=0.21$, see Table 5, Model 3), 
Table 3. Means and standard deviations $(n=645)$.

\begin{tabular}{ccc}
\hline Variable & Scores & Mean (SD) \\
\hline Global Perspective Scale & $0-100$ & $64.5(10.8)$ \\
Age & Years & $17.0(0.33)$ \\
Male & $0-100$ & $42.2(49.5)$ \\
Education level & $0-100$ & $50.2(12.6)$ \\
Paternal educational attainment & $0-100$ & $74.8(24.4)$ \\
Maternal educational attainment & $0-100$ & $69.7(26.3)$ \\
Household income & $0-100$ & $70.7(29.7)$ \\
District GDP & $0-100$ & $67.2(40.2)$ \\
\hline
\end{tabular}

Table 4. Bivariate analysis of respondent background factors and global perspective.

\begin{tabular}{ccccccc}
\hline & $\begin{array}{c}\text { Global } \\
\text { perspective }\end{array}$ & Age & Male & $\begin{array}{c}\text { Educational Paternal educational Maternal educational } \\
\text { attainment }\end{array}$ & $\begin{array}{c}\text { Household } \\
\text { attainment }\end{array}$ & \\
income
\end{tabular}

${ }^{*} \mathrm{p}<0.05^{* *} \mathrm{p}<0.01{ }^{* * *} \mathrm{p}<0.001$.

Table 5. Standardized effects on global perspective.

\begin{tabular}{cccc}
\hline Predictor & Model 1 & Model 2 & Model 3 \\
Age & -0.02 & -0.01 & 0.00 \\
Male & -0.07 & $-0.08^{*}$ & $-0.08^{*}$ \\
Educational attainment & 0.01 & 0.00 & -0.00 \\
Paternal educational attainment & $0.13^{\star *}$ & 0.07 & 0.09 \\
Maternal educational attainment & $0.12^{*}$ & -0.01 & 0.01 \\
Household income & & $0.26^{* * *}$ & $0.21^{* * *}$ \\
District GDP & & 0.01 & -0.01 \\
$R^{2}$ & & & $0.17^{* * *}$ \\
$\Delta R^{2}$ & 0.06 & 0.09 & 0.12 \\
Household income district GDP & 0.06 & 0.03 & 0.03 \\
\hline
\end{tabular}

${ }^{*} \mathrm{p}<0.05^{* *} \mathrm{p}<0.01{ }^{* *} \mathrm{p}<0.001$.

lending support to Hypothesis 1. District GDP, however, demonstrated no significant effect on global perspective, thus disproving Hypothesis 2. The interaction between household income and district GDP showed a positive effect on 
global perspective, supporting Hypothesis $3(\beta=0.17)$.

The results of our study provide support for two of our three hypotheses. Such support of the hypotheses suggests the usefulness of resource theory in understanding global perspective within the contemporary Chinese context. This is particularly the case in more economically developed Chinese cities where there is relatively high household incomes (and also high income disparity) and significant public investment [41]. First, the current findings show that a relatively high household income contributes to global perspective. As previous research has shown, a substantial household income allows individuals to build intercultural competencies by studying abroad, pursuing intercultural experiences and learning foreign languages, and thus to maintain a competitive edge in an era of globalization that is full of uncertainties [20].

District GDP is generally a good proxy of the resources of local governments. Education is always a high priority for these district governments. Nevertheless, our findings illustrate that district GDP displays no significant effect on global perspective. In a departure from earlier studies [29], our study found that a relatively high GDP does not necessarily encourage a global perspective. This finding may be explained by several factors, including the specific manner of investment in global perspective education and the methods of teaching global perspective. Or it may be explained by the degree of accessibility of certain resources. District GDP is not a resource that individuals can easily access unlike household income, unless its distribution and accessibility is user-friendly and guaranteed by policy design or social rights [1]. Individuals relying on the public resources made available by district GDP to enhance their global perspective might be more passive and less able to exert control over the manner of appropriation of such resources, than those relying on household income. If district GDP does not have significant effect on global perspective, it would be useful to examine carefully the manner of investment in and distribution of global perspective education.

Despite the insignificant effect of district GDP on global perspective, the second major finding of this study is the positive interaction effect between household income and district GDP on global perspective. The positive interaction effect shows the benefits of utilizing the two resources, household income and district GDP, simultaneously and reinforces the principle of resource theory that the interaction of two resources enhances desirable outcomes [1] [31].

\section{Managing Inequality by Maximizing Public Resources' Contributions}

If district GDP does not have significant effect on global perspective, but possesses a positive interactive effect with private resources, it would be useful to examine carefully the manner of investment in and distribution of global perspective education. As noted above, the manner of education investment and distribution could be relevant. In general, district GDP support local governmental 
educational spending policies, and a higher GDP leads to greater educational investment that can be used for various relevant initiatives, such as adapting the curriculum, acquiring technology, employing teachers with foreign training, and undertaking exchanges related to global perspective education. Such resources allow schools to create an infrastructure that provides the base for the development of global perspective.

The manner of distributing public resources is left to the schools. With the spending mainly on the infrastructure and technology, students with higher household incomes can use the financial resources of their families to build on that foundation and develop a more advanced knowledge of global perspective. For example, while all students develop basic language skills at school, those with higher household incomes can upgrade their skills with private tutoring, overseas trips and other means. Alternatively, the positive interactive effect of household income and district GDP on global perspective could also be explained by the degree of skill and knowledge that is brought to bear in accessing and utilizing potential public resources. This points to the need to encourage equal opportunities to access and use global perspective resources.

Household income and district GDP should be taken into account when developing global perspective educational policies to ensure that those with lower household incomes have equal access [42]. Equal access, without any barriers due to limited private resources, must be pursued so that students from lower household income families can enjoy the opportunities available. The providers of these resources and opportunities should be sensitive and proactive, reaching out to those students and their parents.

Our findings did indicate that in this interactive relationship, public resources can moderate the effect of household income on global perspective ( $\beta=0.26$ decreased to 0.21 ). We need to address how to further this positive impact. As noted, we suggest policies that target students with lower household incomes, which is in accordance with the Chinese government's aim to build a cohesive and harmonious society through minimizing inequality [43].

In conclusion, our study discusses the independent and interaction effects of household income and district GDP on global perspective, which is essential under globalization. Only household income, a proxy of private resource, showed an independent positive effect on global perspective. Notably, the interaction between household income and district GDP had a positive effect on global perspective. Theoretically, these significant findings show a proliferation of resource theory because of its suitability to understand global perspective, particularly in the Chinese context. Practically, such findings imply the limitations in the manner of public resources distribution. Consequently, we argue that public resources should be more targeting to students with lower household incomes that we can minimize the gap created by private resources, enhancing the equality and accessibility of utilizing global perspective resources.

This study, notwithstanding its novel findings, has certain limitations. It is a 
cross-sectional study, in which the causal associations among variables are debatable. There is still a need for future longitudinal studies to clarify the causal relationships among the resources contributing to global perspective. The study sample was recruited from the student body of senior high schools in Shenzhen, which is a city with robust economic development. As such, it represents only a specific group and cannot be extended to high-school students in general. In future studies, data should be collected from students with diverse backgrounds to strengthen the general application of the findings. Finally, this study relied on a self-administered questionnaire, which can be biased. Future studies using diverse data sources and data collection methods are recommended.

\section{Acknowledgements}

The research is funded by the Shenzhen Philosophy and Social Science "13th Five" Planning Project scheme (135B039).

\section{Conflicts of Interest}

The authors declare no conflicts of interest regarding the publication of this paper.

\section{References}

[1] Smith, W, C., Fraser, P., Chykina, V., Ikoma, S., Levitan, J., Liu, J. and Mahfouz, J.R. (2017) Global Citizenship and the Importance of Education in a Globally Integrated World. Globalisation, Societies and Education, 15, 648-665. https://doi.org/10.1080/14767724.2016.1222896

[2] Rao, M, A., Berry, R., Gonsalves, A., Hastak, Y., Shah, M. and Roeser, R.W. (2013) Globalization and the Identity Remix among Urban Adolescents in India. Journal of Research on Adolescence, 23, 9-24. https://doi.org/10.1111/jora.12002

[3] Parker, W.C. (2011) "International Education" in US Public Schools. Globalisation, Societies and Education, 9, 487-501. https://doi.org/10.1080/14767724.2011.605330

[4] Caruana, V. (2014) Re-Thinking Global Citizenship in Higher Education: From Cosmopolitanism and International Mobility to Cosmopolitanisation, Resilience and Resilient Thinking. Higher Education Quarterly, 68, 85-104. https://doi.org/10.1111/hequ.12030

[5] Merryfield, M.M. (1991) Preparing American Secondary Social Studies Teachers to Teach with a Global Perspective: A Status Report. Journal of Teacher Education, 42, 11-20. https://doi.org/10.1177/002248719104200103

[6] Zhang, R., Hsu, H.-Y. and Wang, S.-K. (2010) Global Literacy: Comparing Chinese and US High School Students. Multicultural Education and Technology Journal, 4 76-98. https://doi.org/10.1108/17504971011052304

[7] UNESCO (2017) The ABCs of Global Citizenship Education. http://unesdoc.unesco.org/images/0024/002482/248232e.pdf

[8] OECD (2016) Global Competency for an Inclusive World. OECD, Paris.

[9] Hanvey, R.G. (1982) An Attainable Global Perspective. Theory into Practice, 21, 162-167. https://doi.org/10.1080/00405848209543001

[10] Case, R. (1993) Key Elements of a Global Perspective. Social Education, 57, 318-325. 
[11] Diener, E. and Fujita, F. (1995) Resources, Personal Strivings, and Subjective Well-Being: A Nomothetic and Idiographic Approach. Journal of Personality and Social Psychology, 68, 926-935. https://doi.org/10.1037/0022-3514.68.5.926

[12] Veeck, G, Pannell, C.W., Huang, Y. and Bao, S. (2016) China' s Geography: Globalization and the Dynamics of Political, Economic, and Social Change. 3rd Edition, Rowman and Littlefield, Lanham, MD.

[13] Lowe, T.S. and Wallace, M. (2017) Occupational Race Segregation, Globalization, and White Advantage: White-Black Earnings Inequality in U.S. Metropolitan Areas. Sociological Spectrum, 37, 353-370. https://doi.org/10.1080/02732173.2017.1365028

[14] Osler, A. and Starkey, H. (2018) Extending the Theory and Practice of Education for Cosmopolitan Citizenship. Educational Review, 70, 31-40. https://doi.org/10.1080/00131911.2018.1388616

[15] Gibson, K, L., Rimmington, G.M. and Landwehr-Brown, M. (2008) Developing Global Awareness and Responsible World Citizenship with Global Learning. Roeper Review, 30, 11-23. https://doi.org/10.1080/02783190701836270

[16] Granzin, K.L. and Haggard, L.M. (2000) An Integrative Explanation for Quality of Life: Development and Test of a Structural Model. In: Diener, E. and Rahtz, D.R., Eds., Advances in Quality of Life Theory and Research, Springer, Dordrecht, 31-64. https://doi.org/10.1007/978-94-011-4291-5_3

[17] Diener, E. and Lucas, R.E. (2000) Explaining Differences in Societal Levels of Happiness: Relative Standards, Need Fulfillment, Culture, and Evaluation Theory. Journal of Happiness Studies, 1, 41-78. https://doi.org/10.1023/A:1010076127199

[18] Adato, M., Devereux, S. and Sabates-Wheeler, R. (2016) Accessing the "Right" Kinds of Material and Symbolic Capital: The Role of Cash Transfers in Reducing Adolescent School Absence and Risky Behaviour in South Africa. The Journal of Development Studies, 52, 1132-1146. https://doi.org/10.1080/00220388.2015.1134776

[19] Mori, J. and Takeuchi, J.D. (2016) Campus Diversity and Global Education: A Case Study of a Japanese Program. Foreign Language Annals, 49, 146-161. https://doi.org/10.1111/flan.12182

[20] Tran, L.T. (2016) Mobility as "Becoming": A Bourdieuian Analysis of the Factors Shaping International Student Mobility. British Journal of Sociology of Education, 37, 1268-1289. https://doi.org/10.1080/01425692.2015.1044070

[21] Shenzhen Statistics Bureau (2018) Shenzhen Statistics Yearbook 2017. China Statistics Press, Beijing.

[22] Baoan District Education Bureau (2014) Baoan District of Shenzhen City's Action Plan on Accelerating the Internationalization of Education (2014-2020). Baoan District Education Bureau, Shenzhen.

[23] Futian District Education Bureau (2016) The 13th Five-Year Plan for Educational Development of Futian District of Shenzhen City (2016-2020). Futian District Education Bureau, Shenzhen.

[24] Cristina, M.V. and Suzana, D. (2015) Measuring Development through Human Resources: The Case of Romania. Annals-Economy Series, 2, 124-131.

[25] Akhoondnejad, A. (2016) Tourist Loyalty to a Local Cultural Event: The Case of Turkmen Handicrafts Festival. Tourism Management, 5, 468-477. https://doi.org/10.1016/j.tourman.2015.06.027

[26] Schutte, I.W., Kamans, E., Wolfensberger, M.V.C. and Veugelers, M. (2017) Preparing Students for Global Citizenship: The Effects of a Dutch Undergraduate Honors Course. Education Research International, 2017, Article ID: 3459631. 
https://doi.org/10.1155/2017/3459631

[27] Siczek, M.M. and Engel, L.C. (2017) Teachers' Cognitive Interpretation of U.S. Global Education Initiatives. Educational Policy.

https://doi.org/10.1177/0895904817719517

[28] Shenzhen City Education Bureau (2015) Guiding Opinion on the Comprehensive Deepening of Secondary and Primary Education Curriculum Reform. Shenzhen City Education Bureau, Shenzhen.

[29] Zhao, Y. (2010) Preparing Globally Competent Teachers: A New Imperative for Teacher Education. Journal of Teacher Education, 61, 422-431. https://doi.org/10.1177/0022487110375802

[30] Sjoquist, D.L. and Winters, J.V. (2012) State Merit-Based Financial Aid Programs and College Attainment. Journal of Regional Science, 55, 364-390. https://doi.org/10.1111/jors.12161

[31] Cheung, C.K., Wang, L.R. and Chan, R.K.H. (2013) Differential Impacts of Stressors on Sense of Belonging. Social Indicators Research, 113, 277-297. https://doi.org/10.1007/s11205-012-0092-y

[32] Fujimura, M. (2000) The Welfare State, the Middle Class, and the Welfare Society. Review of Population and Social Policy, 9, 1-23.

[33] Robson, W.A. (1976) The Welfare State and Welfare Society. George Allen and Unwin, London.

[34] Gilbert, N. (1983) Capitalism and the Welfare State. Yale University Press, New Haven.

[35] Chao, L.-T. and Chou, H.-M. (2017) The Implementation of Intergenerational Green Energy Programs in Nursing Homes and Its Prospects. International Conference on Applied System Innovation, Sapporo, 13-17 May 2017, 1419-1422. https://doi.org/10.1109/ICASI.2017.7988174

[36] Gao, Y., Jia, Z. and Zhou, Y. (2015) EFL Learning and Identity Development: A Longitudinal Study in 5 Universities in China. Journal of Language, Identity and Education, 14, 137-158. https://doi.org/10.1080/15348458.2015.1041338

[37] Erola, J., Jalonen, S. and Lehti, H. (2016) Parental Education, Class and Income over Early Life Course and Children's Achievement. Research in Social Stratification and Mobility, 44, 33-43. https://doi.org/10.1016/j.rssm.2016.01.003

[38] Barrows, T.S., Ager, S.M., Bennett, M.F., Braun, H.I., Clark, J.L.D., Harris, L.G. and Klein, S.F. (1981) College Students' Knowledge and Beliefs: A Survey of Global Understanding. Change Magazine Press, New Rochelle.

[39] Braskamp, L.A., Braskamp, D.C., Merrill, K.C. and Engberg, M. (2014) Global Perspective Inventory (GPI): Its Purposes, Construction, Potential Uses, and Psychometric Characteristics. Global Perspective Institute, Chicago.

[40] Preston, C.C. and Colman, A.M. (2000) Optimal Number of Response Categories in Rating Scales: Reliability, Validity, Discriminating Power, and Respondent Preferences. Acta Psychologica, 104, 1-15. https://doi.org/10.1016/S0001-6918(99)00050-5

[41] Shenzhen Innovative Development Research Institute (2017) Shenzhen: From Speed, Quality to Sharing. http://www.aisixiang.com/data/103220.html

[42] Higgins, S. and Pereira, C. (2014) The Effects of Brazil's Taxation and Social Spending on the Distribution of Household Income. Public Finance Review, 42, 346-367. https://doi.org/10.1177/1091142113501714

[43] Huang, J. (2014) Building a Shared and Harmonious Society in China: An Ethnic Minority Perspective. Development, 57, 77-83. https://doi.org/10.1057/dev.2014.23 